\section{LETTERS TO THE EDITOR}

Individualised pulse oximetry limits in neonatal intensive care

EDIToR,-Gupta et al ${ }^{1}$ have successfully demonstrated that they were unable to accurately predict $\mathrm{PaO}_{2}$ from saturation monitoring even after standardising from a previous measurement. The rest of the conclusions presented in their discussion are however based upon interpretation of other research findings which is not further supported by their own study.

They correctly point out that the poor relation between $\mathrm{SpO}_{2}$ and $\mathrm{PaO}_{2}$ is related to differing proportions of fetal haemoglobin, $\mathrm{PCO}_{2}$, and acid-base balance. This begs a question, which their discussion fails to address, on whether the $\mathrm{PaO}_{2}$ or the $\mathrm{SpO}_{2}$ is the most useful index of oxygenation. It is certainly the case that normal in utero $\mathrm{PO}_{2}$ is within a range which they would describe as "hypoxic". On the other hand, in the presence of $100 \%$ fetal haemoglobin, a saturation monitor should, in these circumstances, correctly indicate adequate saturation.

The authors also remark that transcutaneous oxygen monitoring is "a better way of non-invasively assessing $\mathrm{PaO}_{2}$ ". They provide no evidence for this remark. It is certainly a common experience to find a saturation monitor alarming high when a transcutaneous monitor is apparently recording a norma or even low $\mathrm{PO}_{2}$ because of an undetected poor contact. It is also not the case that transcutaneous oxygen monitoring, particularly on the extremely premature infant, is entirely "non-invasive".

In the long run, the purpose of oxygen monitoring is to detect degrees of hypoxia which are likely to cause acidosis or tissue damage and levels of hyperoxia which may risk retinopathy of prematurity. To date there would appear to be no study comparing different measurement methods with respect to these outcomes. However, the authors' own discussion of the reasons for the poor correlation between $\mathrm{SpO}_{2}$ and $\mathrm{PaO}_{2}$ provides an excellent theoretical argument in favour of the former over the latter!

ROLLO CLIFFORD Consultant Paediatrician, Dorset County Hospital, Williams Avenue, Dorchester, Dorset DT1 2FY, UK

1 Gupta R, Yoxall CW, Subedhar N, Shaw NJ. Individualised pulse oximetry limits in neonatal intensive care. Arch Dis Child Fetal Neonatal Ed 1999;81:F194-6.

\section{Dr Yoxall and Dr Shaw respond:}

Dr Clifford has raised the important question of whether $\mathrm{PaO}_{2}$ or $\mathrm{SpO}_{2}$ is the best index of arterial oxygenation. The answer to this question is, of course, unknown and the aim of our study was not to attempt to provide an answer. Most of the work defining hypoxia and harmful hyperoxia in neonates was performed in the era prior to pulse oximetry and therefore defines these situations in terms of partial pressure rather than oxyhaemoglobin saturation. The guidelines for good practice in the management of neonatal respiratory distress syndrome published by BAPM and RCP state that arterial blood sampling is the "gold standard" for assessing arterial oxygenation. ${ }^{1}$ In the absence of evidence to the contrary, we would agree with this.

Pulse oximetry is very widely used during neonatal intensive care. Our study has shown that it is not possible to accurately predict $\mathrm{PaO}_{2}$ from $\mathrm{SpO}_{2}$ even after standardising from a previous measurement. The information provided by measurements of $\mathrm{PaO}_{2}$ and $\mathrm{SpO}_{2}$ is different and should not be interpreted as interchangeable. As $\mathrm{SpO}_{2}$ monitoring is non-invasive, semicontinuous, and has a rapid response time, it useful for monitoring trends and particularly in detecting episodes of sudden deoxygenation.

Monitoring of $\mathrm{PaO}_{2}$ is possible using transcutaneous monitoring and this is a better way of continuously monitoring $\mathrm{PaO}_{2}$ than trying to extrapolate from the $\mathrm{SpO}_{2}$ signal. The ease with which pulse oximetry can be applied has led to the virtual abandonment of transcutaneous monitoring by many units. There are technical difficulties with transcutaneous monitoring as pointed out by Dr Clifford, but these can be overcome if the staff caring for the babies are familiar with the technique and use it on a routine basis. The anecdotal experiences of those units that continue to use transcutaneous monitoring as part of their clinical routine is that it remains an extremely useful technique.

The purpose of maintaining adequate arterial oxygenation is to provide oxygen to meet the metabolic demands of the baby, prevent pulmonary hypertension, and avoid oxygen toxicity. We do not have a satisfactory method of defining what constitutes adequate oxygenation during intensive care at present and it is necessary to take into account other variables, such as haemoglobin concentration or tissue perfusion, which also determine oxygen delivery when we assess our patients.

1 Anonymous. Development of audit measures and guidelines for good practise in the management of neonatal respiratory distress syndrome. Report of a joint working party of the British Association for Perinatal Medicine and the Research Unit of the Royal College of Physicians. Arch Dis Child 1992;67:1221-7.

\section{Apnoea following immunisation in} premature infants

EDITOR,-Slack and Schapira ${ }^{1}$ are correct in drawing attention to a problem that is recognised and documented but not fully addressed or understood. Their suggestion that further studies are required to determine the optimum timing of immunisation for extremely preterm infants is sound (even though the adequate immunological response of these babies to vaccinations is well documented).

However they state that the presumed cause of the apnoeas is the pertussis component, with neither reference nor explanation of why they think this is the case. As the four antigens are given simultaneously it is not possible to identify the culprit. The American studies quoted ${ }^{2}$ could not identify whether one or a combination of antigens was the cause or indeed whether one of the several other substances contained within vaccines contributed to the reaction. Indeed Sanchez et al merely postulate that pertussis is the most likely reason because it has been reported in the past to provoke more local and systemic reactions, although the incidence of associated reactions in their cohort was low. ${ }^{2}$ Botham et al claim that pertussis endotoxin acting centrally may stimulate apnoeas $^{3}$ although there is no evidence for this. To determine this matter a randomised controlled trial of whole cell pertussis, acellular pertussis, and placebo would be required Plainly this is not an ethical or practical option, hence it would seem sensible to follow the suggested advice of monitoring these infants for 48 hours, especially in very low birth weight infants and those with chronic lung disease. The effects of implementing acellular pertussis vaccine will be awaited with interest.

In view of recent and not so recent media hysteria of unconfirmed (and indeed discounted $^{4}$ ) claims of the adverse effects of vaccines, we should not be fuelling this matter by making suppositions which cannot yet be supported by the scientific evidence.

D J STALKER Specialist Registrar, Bristol Royal Hospital for Sick Children, St Michael's Hill, Bristol BS2 8BF, UK

1 Slack MH, Schapira D. Severe apnoeas following immunisation in premature infants. Arch Dis Child 1999;81:F67-8.

2 Sanchez PJ, Laptook AR, Fisher L, et al. Apnea after immunisation of preterm infants. $\mathcal{F}$ Pediatr 1997;130:746-51

3 Botham SJ, Isaacs D, Henderson-Smart DJ. Incidence of apnoea and bradycardia in preterm infants following $\mathrm{DTP}_{\mathrm{w}}$ and $\mathrm{Hib}$ immunisation: a prospective study. $\mathcal{F}$ Paediatr Child Health 1997;33:418-21.

4 Anonymous. The safety of MMR vaccine. Current Problems in Pharmacovigilance 1999;25:9-10.

\section{Dr Slack and Dr Schapira respond:}

We thank Dr Stalker for his comments about our report. He is quite correct that neither we nor any of those authors who have previously described these events have provided any evidence that it is either the pertussis component of the diphtheria/tetanus/whole cell pertussis vaccine or its endotoxin content that is responsible for these reactions. That is why we described it as "the presumed cause".

It is possible that any of the vaccine components or adjuvants are responsible. It may simply be a response to pain, although this seems unlikely. However, given the evidence of reduced local and systemic reactions with acellular pertussis vaccines in term infants compared with the UK whole cell vaccine, ${ }^{1}$ it seems plausible that the pertussis component may be involved.

$\mathrm{He}$ is partially correct in stating that the way to answer this would be to conduct a three way randomised trial between placebo, acellular (DTaP), and whole cell pertussis (DTwP) vaccines. In fact, it would require multiple randomisations between $\mathrm{Hib}, \mathrm{DT}$, DTwP, one, two, three, and five component $\mathrm{DTaP}$ vaccines, and placebo. Even if the use of a placebo were ethically acceptable, which we agree would not be the case, the low incidence of these events would make the number of infants required for such a study impossibly large.

We are, however, conducting a multicentre study to determine the incidence of apnoeas following immunisation using a three component acellular vaccine.

Finally, we do not accept that we have joined the ranks of those who have shaken confidence in the vaccination programme. 
The question is not whether preterm infants should be immunised against pertussis but when and with what vaccine.

1 Olin P, Rasmussen F, Gustafsson L, Hallander HO, Heijbel H. Randomised controlled trial of $\mathrm{HO}$, Heijbel $\mathrm{H}$. Randomised controlled trial of two-component, three-component, and fivepared with whole-cell pertussis vaccine. Lancet 1997;350:1569-77.

\section{Randomised controlled trial of cisapride in preterm infants}

EDITOR,-I read with great interest the study by $M c C l u r e$ et $a l^{1}$ reporting delayed gastric emptying and a non-significant increase in whole gut transit time in premature infants treated with cisapride. ${ }^{1}$ In contrast, placebo controlled studies evaluating cisapride in paediatrics have almost consistently reported improvement in symptoms of gastrooesophageal reflux diseases or improvement in oesophageal $\mathrm{pH}$ results and/or manometry. ${ }^{2} \mathrm{As}$ acknowledged by the authors, other studies in premature infants have reported a reduction in gastric residue and improved feed tolerance. In addition, we have reported a reduction in gastro-oesophageal reflux in premature infants. $^{3}$

In this latest trial the authors chose hydroxypropylmethyl cellulose as a placebo, given at the "same volume" as cisapride; however, the actual quantity administered is not clear. Cellulose derivatives are commonly employed as laxatives, where it is proposed that they act by absorbing water, so softening the faeces and increasing stool volume. This in turn stimulates faecal propulsion. ${ }^{4}$ Clearly, depending on the dose of hydroxypropylmethyl cellulose used, the choice of this compound as a placebo is nonsensical as there could be a marked impact on gastrointestinal transit time. From the publication it is also not clear why gastrointestinal motility was measured after three days dosing; it is likely that any cathartic effect from a laxative would be less marked after more prolonged treatment time.

The manufacturer had recommended against the use of cisapride in premature infants because of concern that the metabolic pathway of cisapride may not be fully developed. However, in most European countries and the United States, cisapride is commonly used in premature (gestational age $>34$ weeks) infants, and, despite this widespread use, the incidence of clinically important cardiovascular effects is very low. Such events are often associated with high doses (>0.8 mg/kg/day) or concomitant administration of drugs known to inhibit cytochrome P450 that, like cisapride, are known to prolong the QT interval. ${ }^{2}$

In my opinion, in view of the clinical experience with cisapride in severe gastrooesophageal reflux disease and feed intolerance in premature infants, and the few clinically relevant cardiovascular events, treatment with cisapride with appropriate monitoring (electrocardiogram before and after two or three days of treatment) should not be withheld from these infants if clinically indicated.

YVAN VANDENPLAS Academic Children's Hospital Free University of Brussels Laarbeeklaan 101

1090 Brussels, Belgium

1 McClure RJ, Kristensen JH, Grauaug A Randomsied controlled trial of cisapride in preterm infants. Arch Dis Child Fetal Neonatal Ed 1990;80:F174-7.

2 Vandenplas Y. Clincial use of cisapride and its risk-benefit in paediatric patients. Eur $\mathcal{F}$ Gastroenterol Hepatol 1998;10:871-81.

3 Vandenplas Y, Sacre L, Loeb H. The effect of cisapride on gastric stasis and gastrooesophageal reflux in premature infants. In Johnson AG, Lux G, eds. Progress in the treatment of gastrointestinal motility disorders: the role of cisapride. Amsterdam; Excerpta Medica, 1989:158-63.

4 Binder HJ. Pharmacology of laxatives? Annu Rev Pharmacol Toxicol 1977;17:355-67.

\section{Dr McClure responds:}

We agree, and indeed stated in our own paper ${ }^{1}$ that cisapride has been shown in children to improve symptoms of gastrooesophageal reflux disease and to hasten both gastric emptying and gastrointestinal transit time. We believe that it is dangerous to assume that the immature gas of the preterm infant will react in the same manner. We further believe that our study has the strongest methodology of any published that has directly examined the effect of cisapride on gastrointestinal motility in the preterm infant. As stated in our discussion, we did not measure gastro-oesophageal reflux and so cannot comment on the efficacy of cisapride for this condition. However, in view of our findings, until there is published evidence in a peer reviewed journal of cisapride's efficacy for this condition, we hold to our concluding statement that it should be contraindicated as recommended by the Medicines Control Agencies. $^{2}$

We do not believe that the choice of hydroxypropylmethyl cellulose as a placebo inadvertently affected our study. The formulation of cisapride suspension used in our study contained hydroxypropylmethyl cellulose. This was why this agent was chosen as placebo. The strength of cisapride was 1 $\mathrm{mg} / \mathrm{ml}$, and therefore infants typically received $0.2-0.3 \mathrm{ml}$ per dose when receiving placebo. Cellulose derivatives act as laxatives by increasing faecal bulk. We do not believe that an aqueous solution of this volume to be anywhere near sufficient to cause this effect. Lastly, the significant finding of our study was delayed gastric emptying time during cisapride treatment, not whole gastrointestinal transit time.

The pharmacokinetics of cisapride in the preterm infant are unclear. A period of three days dosing before measurement of gastrointestinal motility was considered necessary to allow both time for acquisition of a steady serum cisapride level and adequate elimination of any previous cisapride treatment.

1 McClure RJ, Kristensen JH, Grauaug A Randomsied controlled trial of cisapride in preterm infants. Arch Dis Child Fetal Neonatal Ed 1990;80:F174-7.

2 Committee on the Safety of Medicines Medicines Control Agency. Cisapride (Prepulsid): risk of arrhythmias. Current Problems pulsid): risk of arrhythmias. Cur
in Pharmacovigilance 1998;24:11.

\section{The use of cisapride in neonates}

EDITOR,-In response to the annotation of Markiewicz and Vandenplas, ${ }^{1}$ in which they give the indications for the use of cisapride in neonates, I performed a Medline search using the search terms "cisapride" and "infant, newborn". This disclosed only three randomised controlled trials of cisapride versus placebo in neonates. ${ }^{2-4}$ One other study compared cisapride with placebo in infants, but only a subgroup of this study population were neonates (number not stated). ${ }^{5}$ None of these studies were referenced in their annotation Surely in these days of evidenced based medicine, direct examination of the evidence available is mandatory.

The results of the trials found in my search show that cisapride is only effective in: treating ileus after abdominal surgery ${ }^{4}$; reducing the number of gastric residuals in nasogastrically fed preterm infants ${ }^{3}$; and decreasing the incidence of regurgitation in preterm infants. ${ }^{3}$ Specifically cisapride was not effective in reducing the time taken to achieve full enteral feeds in preterm infants, ${ }^{3}$ and may delay gastric emptying in preterm infants.

Furthermore it could be argued that gastro-oesophageal reflux is a nonpathological state in neonates, and only if it leads to complications (secondary respiratory disease, oesophagitis) does it require treatment. No randomised controlled trial of cisapride versus placebo in neonates has been published that looks at these clinically relevant outcomes.

I would therefore argue that, given the side effect profile, the only indications for cisapride in neonates are treatment of postoperative ileus and, possibly, treatment of regurgitation leading to complications. At present there is no evidence that it is effective for use in neonates in any other circumstance.

MARK W DAVIES Perinatal Research Centre University of Queensland Royal Women's Hospital Brisbane, Australia 4029

1 Markiewicz M, Vandenplas Y. Should cisapride have been "blacklisted"? Arch Dis Child Fetal Neonatal Ed 2000;82:F3-4.

2 McClure RJ, Kristensen JH, Grauaug A. Randomised controlled trial of cisapride in preterm infants. Arch Dis Child Fetal Neonatal Ed 1999;80:F174-7.

3 Enriquez A, Bolisetty S, Patole S, Garvey PA, Campbell PJ. Randomised controlled trial of cisapride in feed intolerance in preterm infants. Arch Dis Child Fetal Neonatal Ed 1998;79:F110-13.

4 Lander A, Redkar R, Nicholls G, et al. Cisapride reduces neonatal postoperative ileus: ranreduces neonatal postoperative ileus: ran-
domised placebo controlled trial. Arch Dis Child Fetal Neonatal Ed 1997;77:F1 19-22.

5 Vaneygen $M$, Vanravensteyn $H$. Effect of cisapride on excessive regurgitation in infants. Clin Ther 1989;11:669-77.

Mechanism of blood pressure increase induced by dopamine in hypotensive preterm neonates

EDIToR,-The paper of Zhang et al ${ }^{1}$ on the effects of dopamine relies on the assumption that left ventricular output (LVO) is a measure of systemic blood flow (SBF). This is not true in the presence of any shunt through the ductus arteriosus where LVO becomes the sum of SBF and volume of blood shunting back into the lungs through the duct, and so overestimates SBF. While Zhang et $a l^{1}$ define the ducts in their study babies as insignificant, we would question the validity of the criteria used to make this definition. We have never seen shunting only in diastole, chamber enlargement is an inconsistent sign of ductal significance which develops after day one, ${ }^{2}$ and shunt velocity has little relation to shunt size during week one. ${ }^{3}$ In fact, the left to right velocity often increases as the duct constricts and the shunt diminishes in size. ${ }^{3}$ Bidirectional shunting is also usually predominantly left to right.

There is much in the data presented by Zhang et $a l^{1}$ to suggest that these ducts were highly significant. Firstly, they selected a population at high risk for a significant duct, ${ }^{4}$ 
A

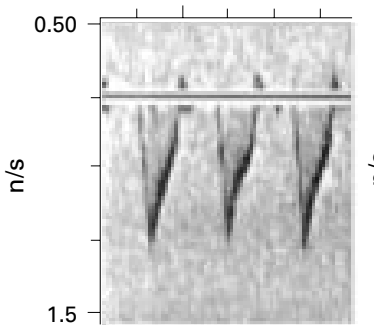

B

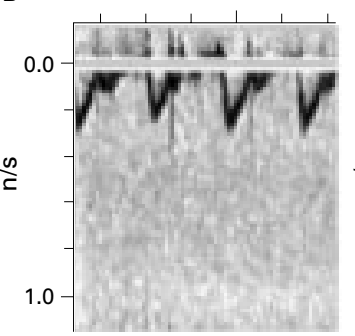

C

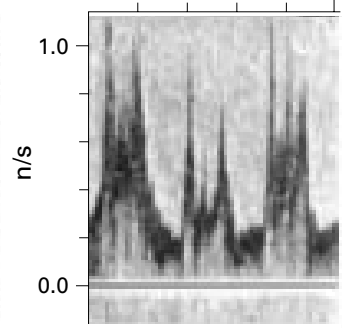

Figure 1 Doppler measures taken from a 26 week infant at 5 hours of age. (A) High velocity flow (about $1.0 \mathrm{~m} / \mathrm{s}$ ) in the ascending aorta representing a left ventricular output of $350 \mathrm{ml} / \mathrm{min}$ per $\mathrm{kg}$. (B) Low velocity flow (about $0.2 \mathrm{~m} / \mathrm{s}$ ) in the pulmonary artery representing a right ventricular output of $90 \mathrm{ml} / \mathrm{min}$ per $\mathrm{kg}$. (C) Low velocity (about $0.7 \mathrm{~m} / \mathrm{s}$ ) high volume laminar left to right flow through an unconstricted duct.

and secondly they measured a mean diameter of $2.9 \mathrm{~mm}$. We showed that this measure is the most accurate predictor of early haemodynamic significance and that preterm ducts over $2 \mathrm{~mm}$ in diameter, with very few exceptions, have a haemodynamic impact. ${ }^{35}$ In this haemodynamic milieu, LVO is actually a measure of pulmonary blood flow, and right ventricular output becomes the better measure of SBF, ${ }^{5}$ but even this can be confounded by the common finding of left to right atrial shunting. ${ }^{36}$ That this haemodynamic impact is often present from the very early postnatal period is emphasised in fig 1 which is of a 5 hour old infant of 26 weeks gestation, in whom we measured an LVO of $350 \mathrm{ml} / \mathrm{min}$ per kg but a right ventricular output (RVO) of $90 \mathrm{ml} / \mathrm{min}$ per $\mathrm{kg}$. This baby had an unrestricted duct $(2.6 \mathrm{~mm})$ with a low velocity $(0.7 \mathrm{~m} / \mathrm{s})$ but high volume left to right shunt. In other words LVO was overestimating SBF by a factor of over $300 \%$. This is not an unusual finding. ${ }^{3}$

This means that the changes in LVO in response to dopamine documented by Zhang et $a l^{1}$ may have occurred in the systemic circulation but, equally, could have occurred in the pulmonary circulation. The same uncertainty applies to changes in calculated vascular resistance. In other words, LVO may have increased or decreased solely because dopamine has changed the volume of the ductal shunt back into the lungs.

Early preterm ductal shunting should not be assumed to be inconsequential, and interpretation of early postnatal measures of either right or left ventricular output in preterm infants should be approached with caution.

NICK EVANS DAVID OSBORN MARTIN KLUCKOW Department of Neonatal Medicine King George V Hospital for Mothers and Babies Royal Prince Alfred Hospitals Missenden Road Camperdown NSW 2050, Australia

email:nevans@med.usyd.edu.au

1 Zhang J, Penny DJ, Kim NS, Yu VYH, Smolich JJ. Mechanism of blood pressure increase induced by dopamine in hypotensive preterm neonates. Arch Dis Child Fetal Neonatal Ed 1999;81:F99-104.

2 Iyer P, Evans NJ. Re-evaluation of the left atrial to aortic root ratio as a marker of patent ductus arteriosus. Arch Dis Child Fetal Neonatal Ed 1994;70:F112-17.

3 Evans NJ, Iyer P. Assessment of ductus arteriosus shunting in preterm infants requiring ventilation: effect of inter-atrial shunting. $\mathcal{F}$ Pediatr 1994;125:778-85.

4 Evans NJ, Moorcraft J. Effect of patency of the ductus arteriosus on blood pressure in very preterm infants. Arch Dis Child 1992;67:116973.

5 Evans NJ, Kluckow M. Early determinants of right and left ventricular outputs in ventilated preterm infants. Arch Dis Child Fetal Neonatal Ed 1996;74:F88-94.

6 Evans NJ, Iyer P. Incompetence of the foramen ovale in preterm infants requiring ventilation. f Pediatr 1994;125:786-92.

\section{Dr Zhang et al respond:}

Dr Evans and his colleagues have raised two main issues about our paper. ${ }^{1}$ The first relates to the haemodynamic significance of shunting through the ductus in our subjects. We readily acknowledge that shunting was present and that the measured left ventricular output was therefore an approximation of systemic tissue blood flow. This was unavoidable, as most babies were studied on the first day after birth, when the ductus is proceeding to close. ${ }^{2}$ However, on the basis of clinical assessment as well as other data not presented-for example, average left ventricular shortening fraction was $29 \%$-we considered that myocardial dysfunction rather than ductal shunting was the most likely cause of the systemic hypotension shown.

Our study was confined to a select subgroup of babies with hypotension who failed to respond to volume loading and were thus started on inotropes. In contrast, the studies cited by Evans and colleagues were performed in groups of infants who may or may not have received volume loading and/or inotropic treatment ${ }^{3-7}$ and in whom the level of myocardial function ranged from depressed to normal. ${ }^{6}$ Furthermore, most of our subjects were studied within the initial 24 hours after birth, whereas the studies cited ${ }^{3-7}$ were performed over the course of the first postnatal week. Given the substantial physiological changes in the cardiovascular system, ${ }^{89}$ findings obtained in the middle or end of the initial week may not necessarily be applicable to the first day after birth.

Evans and colleagues state that "left ventricular output may have increased or decreased solely because dopamine changed the volume of the ductal shunt back to the lungs". The physiological changes we observed suggest that this was unlikely and that dopamine exerted a vasoactive effect within the systemic circulation. Thus the premise that the increase in left ventricular output was related only to greater left to right ductal shunting is not in accord with the concomitant rise in systemic blood pressure induced by dopamine. The contention that falls in left ventricular output were merely due to a reduction in ductal shunting is inconsistent with the observed fall in superior mesenteric artery velocity and rise in superior mesenteric vascular resistance.
A possibility deserving of consideration is that dopamine changed the degree of ductal shunting and that this comprised one component of the alteration in left ventricular output. We are not aware of any published data in newborn infants that support direct relaxation or constriction of the ductus by dopamine or of a differential effect of dopamine on the systemic and pulmonary vascular beds. Indeed, in studies performed in newborn lambs, we observed that, at infusion rates of up to $15 \mu \mathrm{g} / \mathrm{min}$ per $\mathrm{kg}$, the systemic and pulmonary vascular effects of dopamine were proportionally similar in magnitude (J J Smolich, H Park, and D J Penny, unpublished observations). In our view therefore it was reasonable to assume that, while ductal shunting was present in our babies, the degree was not altered to a substantial extent by dopamine. However, the notion that inotropic treatment could alter ductal shunting in preterm infants has potentially important clinical ramifications and so is worth investigating.

Finally, although we agree that the illustrative example of the degree of dissociation which may occur between the level of left and right ventricular outputs is striking, examination of group data from the same laboratory suggests that, on average, left ventricular output is only $7-15 \%$ higher than right ventricular output in ventilated preterm infants. ${ }^{6}$ Moreover, while we did not include the data in our paper, the pulmonary trunk velocitytime integral in our infants was not significantly different from the ascending aortic velocity-time integral ( $p>0.9)$, suggesting that the marked degree of dissociation between ventricular outputs evident in the illustrative example was not a feature of the babies in our study.

J J SMOLICH

J ZHANG

D J PENNY

V Y H YU

Centre for Heart and Chest Research Department of Medicine Monash University Department of Paediatrics Monash University

1 Zhang J, Penny DJ, Kim NS, Yu VYH, Smolich JJ. Mechanism of blood pressure increase induced by dopamine in hypotensive preterm neonates. Arch Dis Child Fetal and Neonatal Ed 1999;81:F99-104.

$2 \mathrm{Yu}$ VYH. Patent ductus arteriosus in the preterm infant. Early Hum Dev 1993;35:1-14.

3 Iyer P, Evans NJ. Re-evaluation of the left atrial to aortic root ratio as a marker of patent ductus arteriosus. Arch Dis Child Fetal and Neonatal Ed 1994;70:F112-17.

4 Evans NJ, Iyer P. Assessment of ductus arteriosus shunting in preterm infants requiring ventilation: effect of inter-atrial shunting. 7 Pediatr 1994;125:778-85.

5 Evans NJ, Moorcraft J. Effect of patency of the ductus arteriosus on blood pressure in very preterm infants. Arch Dis Child 1992;67:116973.

6 Evans NJ, Kluckow M. Early determinants of right and left ventricular outputs in ventilated preterm infants. Arch Dis Child Fetal and Neonatal Ed 1996;74:F88-94.

7 Evans NJ, Iyer P. Incompetence of the foramen ovale in preterm infants requiring ventilation. f Pediatr 1994;125:786-92.

8 Walker AM. Circulatory transitions at birth and the control of the neonatal circulation. In: MA Hanson, JAD Spencer, CH Rodeck, eds. Fetus and neonate: physiology and clinical applications. and neonate: physiology and clinical applications. bridge University Press, 1993:160-96.

9 Smolich JJ, Berger PJ, Walker AM. Interrelation Smolich J, Berger PJ, Walker AM. Interrelation between ventricular function, myocardial blood flow and $\mathrm{O}_{2}$ consumption changes at birth in lambs. Am f Physiol 1996;270 
Retained umbilical artery catheter presenting as an umbilical abscess

EDIToR,-We report the delayed recognition of an umbilical artery catheter in an 18 month infant who presented with recurrent umbilical discharge

A male infant was delivered by caesarian section which was complicated by a hypoglycaemic fit. Resuscitation included the attempted insertion of an umbilical venous catheter. The line was found to be arterial and thus removed. A second attempt also entered the umbilical artery, and, as the infant was now stable, no further attempt was made.

At 15 months, the infant presented with an umbilical abscess. This was investigated after drainage to exclude a urachal remnant. An ultrasound and abdominal radiograph showed a foreign body within the common iliac artery, and, using an infraumbilica approach, part of an umbilical catheter was removed. The remnant was $10 \mathrm{~cm}$ in length.

During the neonatal period, the umbilicus is a useful route of vascular access. The umbilical artery can be used for blood pressure and gas tension measurement but all catheters should be removed early to avoid central infection. ${ }^{1}$ Other complications such as thrombosis and necrotising enterocolitis have been reported. ${ }^{2}$ Migration of umbilical vein catheters into the left atrium and pulmonary veins may occur. ${ }^{3}$ Retrieval of fractured umbilical catheters during the neonatal period has been reported. ${ }^{4}$

In this case, the retained catheter was not recognised until the infant presented late with recurrent umbilical infections and illustrates a new addition to our list of differential diagnoses. The history also re-emphasises that it is essential to check central lines for completeness on removal.

R KOTNIS A SALLOUM R HITCHCOCK Department of Paediatric Surgery, fohn Radcliffe Hospital, Oxford

1 Rossi P. Hook catheter technique for transfemoral removal of foreign body from right side of the heart. Am f Roentgenol 1990;108:101-6.

2 Wagner CW, Vinocur CD, Weintraub WH. Retrieval of an umbilical artery catheter: a
potential for misadventure. South Med $f$ 1987;80:1434-5.

3 Ruiz CE, Nystrom GA, Butt AI, Zhang HP. Percutaneous retrieval of a broken umbilical catheter from left atrium in a premature newborn. Cathet Cardiovasc Diagn 1995;36:265-8.

4 Simon-Fayard EE, Kroncke RS, Solarte D, Peverini R. Nonsurgical retrieval of embolised umbilical catheters in premature infants. Perinatol 1997;17:143-7.

Premedication for neonatal intubation: current practice in Australia and the United Kingdom

EDIToR, - The paper by Bhutada $e t a l^{1}$ adds to the growing body of evidence that premedication for tracheal intubation in neonates both improves physiological stability and makes the procedure easier to perform. The results of the telephone survey of premedication use in UK neonatal units by Whyte et $a l^{2}$ helps to define current practice. In a similar study, we recently tried to define the routine use of premedication for tracheal intubation in term and preterm neonates in Australia and the United Kingdom, allowing comparisons to be made.

A survey was conducted of practice in Australian level 3 units (21) and UK units with six or more intensive care cots (52). The for-

Table 1 Results of survey of premedication practice for tracheal intubation in term and preterm neonates in Australia and the United Kingdom

\begin{tabular}{llllll}
\hline & \multicolumn{2}{l}{ United Kingdom } & & \multicolumn{2}{l}{ Australia } \\
\cline { 2 - 3 } \cline { 5 - 6 } & Term & Preterm & & Term & Preterm \\
\hline Routine premedication (\%) & $22(42)$ & $18(34)$ & & $15(71)$ & $14(67)$ \\
Opiate & 13 & 11 & & 2 & 4 \\
BDZ & 1 & 0 & & 2 & 1 \\
Opiate + BDZ & 1 & 1 & & 0 & 0 \\
Opiate + muscle relaxant \pm atropine & 6 & 6 & & 11 & 9 \\
BDZ + muscle relaxant \pm atropine & 1 & 0 & & 0 & 0
\end{tabular}

$\mathrm{BDZ}$, benzodiazepine.

mat was a semistructured telephone interview of the nurse in charge of the shift when the call was made. All interviews were conducted by one of two of the authors (S H and J B) in September 1999. There was a $100 \%$ response rate, and the results are given in table 1 .

Seven different combinations of premedication drugs were in routine use in Australia compared with 14 different combinations in the United Kingdom.

In Australian units, the routine administration of premedication for non-emergency tracheal intubation of term and preterm neonates is common practice, and there is some uniformity in the combinations of drugs used. In contrast, this practice is less common in the United Kingdom and there is more diversity of prescribing. In both countries, premedication was more commonly used for term neonates. This difference in practice may reflect the fact that larger babies are more likely to struggle when intubated, making the procedure more technically demanding.

We agree with Whyte et al that there is a strong evidence based argument for premedication for tracheal intubation in neonates to be routine. Our work brings added clarity to the existing picture and confirms that there is little consensus as to the best combination of drugs to use. Further work to define best practice is urgently required.

STEPHEN HANCOCK Department of Anaesthesia Bradford Royal Infirmary SIMON NEWELL St fames's University Hospital Leeds

JOE BRIERLEY ANDREW BERRY

New South Wales Newborn and Paediatric Emergency Transport Service Wentworthville, NSW, Australia

1 Bhutada A, Sahani R, Rastogi S, Wung J-T. Randomised controlled trial of thiopental for
intubation in neonates. Arch Dis Child Fetal intubation in neonates. Arch

2 Whyte S, Birrell G, Wyllie J. Premedication before intubation in UK neonatal units. Arch Dis Child Fetal Neonatal Ed 2000;82:F38-41.

Perinatal cortical infarction with no obvious cause

EDITOR,- The study by Govaert et al of ultrasonography in newborn infants with perinatal cortical infarctions ${ }^{1}$ did not find a cause in $25 \%$ of cases. They also confirmed an association between stroke and pulmonary hypertension requiring assisted ventilation. ${ }^{2}$

We have previously published observations on artificially ventilated newborn piglets with pneumothorax and pulmonary hypertension, showing cerebral arterial air microembolisations. ${ }^{34}$ In the case of artificial ventilation, which is often accompanied by pulmonary air leak syndrome (pulmonary interstitial em- physema, pneumomediastinum, pneumothorax), air can easily reach the cerebral vasculature, especially when there is persistent pulmonary hypertension and right to left intracardiac shunts.

In the light of our observations, as air microemboli could not be detected by ultrasound, I suspect that the perinatal cortical infarction may have been due to cerebral arterial air embolisation in some patients in the study by Govaert et al.

$$
\begin{array}{r}
\text { PÉTER TEMESVÁRI } \\
\text { Department of Pediatrics } \\
\text { University Teaching Hospital } \\
\text { Kecskemét, Hungary }
\end{array}
$$
email :temespete@hotmail.com

1 Govaert P, Matthys E, Zecic A, Roelens F, Oostra A, Vanzieleghem B. Perinatal cortical infarction within middle cerebral artery trunks. Arch Dis Child Fetal Neonatal Ed 2000;82:F59 63.

2 Klesh KW, Murphy TF, Scher MS, Buchanan DE, Maxwell EP, Guthrie RD. Cerebral infarction in persistent pulmonary hypertension of the newborn. American fournal of Diseases in Children 1987;141:852-7.

3 Temesvári P, Kovács J, Rácz K. Cerebral arterial air embolisation in experimental neonatal pneumothorax. Arch Dis Child 1989;64:179.

4 Temesvári P, Kovács J, Ábrahám CS. Pneumothorax and neonatal stroke. Neuropediatrics 1996;27:167-8.

\section{Neonatal pain relief}

EDITOR, - The study of Jain and Rutter ${ }^{1}$ indicates that, after an hour of application, topical amethocaine gel exerts a demonstrable anaesthetic effect $54.8 \%$ of the time, indicating low potential for practical use. In the authors' own words "a successful . . . anaesthetic should be quick acting, effective and safe ...”.

It is therefore disappointing to note that in the discussion no mention was made of oral sucrose as an analgesic agent for use in neonates undergoing painful procedures. This is despite a large body of evidence suggesting that it reduces the indicators of pain from various sources. ${ }^{23}$ Unfortunately there is a widespread reluctance of clinicians to use oral sucrose before performing painful procedures on neonates. We showed this in a recent study. ${ }^{4}$

Questionnaires were sent to the medical directors of the 18 neonatal units in New Zealand in order to determine the knowledge, attitudes, and practice with regard to commonly performed painful neonatal procedures such as blood taking or line placement. In the 15 replies, there was a high degree of awareness that the procedures caused pain $(100 \%)$, that the physiological stress of pain was more hazardous than the risks of analgesia (67\%), and that oral sucrose was a safe and effective analgesic $(87 \%)$; and yet only five units $(33 \%)$ ever used any type of analgesia for these procedures and usually for less than $10 \%$ of the time. Only one unit (our own) used oral sucrose routinely. We find it to 
be highly effective, simple to use, and rapid in action. It is also exceedingly cheap.

We do not know why oral sucrose has failed to find much favour in neonatal units. Clearly neither lack of understanding of neonatal pain perception nor lack of knowledge about the analgesic properties of sucrose are significant factors. Perhaps there is an unrecognised prejudice against anything that is low tech, cheap, and not promoted by pharmaceutical companies.

PAUL HEATON DAVID HERD

Child and Adolescent Community Centre Taranaki Health Private Bag 2016 New Plymouth 4620, New Zealand email:paed.cacc@thcl.co.nz

1 Jain A, Rutter N. Local anaesthesia effect of topical amethocaine gel in neonates: rantopical amethocaine gel in neonates: ran-
domised controlled trial. Arch Dis Child Fetal Neonatal Ed 2000;82:F42-5.

2 Stevens B, Ohlsson A. Sucrose for analgesia in newborn infants undergoing painful procedures. Cochrane Library, Issue 3. Oxford: Update Software, 1999

3 Ramenghi LA, Wood CM, Griffith GC, Levene MI. Reduction of pain response in premature infants using intraoral sucrose. Arch Dis Child Fetal Neonatal Ed 1996;74:F126-8.

4 Heaton PAJ, Herd DW. Analgesia for simple neonatal procedures: a survey of New Zealand neonatal procedures. a survey of New Zealand Annual Scientific Meeting, Wellington 1999.

\section{BOOK REVIEWS}

Prenatal care. Effectiveness and implementation. Edited by Marie C McCormick and Joanna E Siegel [Pp363; £39.95] Cambridge University Press, 1999. ISBN 0-521-66196-X.

After fifty years, my only real memory of the paediatrics teaching of Professor A V Neale in Bristol is the benefit to children of sunlight and the aphorism "Preconceptual and Prenatal care is crippled by a large proportion of the disadvantaged population who further disadvantage themselves by their own actions". Regrettably this text from the USA shows us that little has changed. Over these decades the rate of prematurity, intrauterine growth retardation (IUGR) and perinatal mortality has changed very little in spite of all our collective clinical efforts.

The male partner is hardly mentioned in this book so it seems that, to American eyes, the sole responsibility for producing healthy or unhealthy babies lies with the mother. All of us now know that many varied vaginal infections are associated with premature/prelabour rupture of the membranes and prematurity itself and that antibiotic treatment may have a reducing effect on these problems. Yet with a close reading of the chapter on vaginal infections, which is very well referenced, there appear to be no papers indicating that with all these infections possibly being sexually transmitted, no trials have included investigation and treatment of the male partner. For example, although Bacterial Vaginosis, Candida and Haemolytic Streptococcus are not usually recognised as sexually transmitted diseases (STD), all gynaecologists have witnessed cases where they have been the cause of recurrent vaginal infections.

Many chapters emphasise the adverse effects of alcohol, smoking, recreation drugs and poverty on the unborn fetus. I have always had a healthily sceptical interest in Jongbloet's ${ }^{1}$ theory that alcohol consumption just before and at the time of conception may be responsible for a large number of chromosomal aberrations but this attractive theory is nowhere to be found in the book.

Meanwhile we are beset by new threats. A recent study, ${ }^{2}$ not mentioned in this book, shows ecstasy exposure being implicated in some congenital anomalies.

This is a well researched book with excellent references. Throughout, areas of research yet to be carried out are mentioned. For that reason alone it could serve as a good "ideas" source book for junior paediatricians and obstetricians to involve themselves in research projects which may one day help to reduce the continuing high incidence of potentially-damaged babies.

JOHN MCGARRY Consultant Obstetrician and Gynaecologist in Independent Practice North Devon

1 Jongbloet PH. Prepregnancy Care: Background Biological Effects. Prepregnancy Care. A Biological Effects. Prepregnancy

2 McElhatton PR, Bateman DN, Evans C, Pughe $\mathrm{KR}$, Thomas SHL. Congenital anomalies after prenatal ecstacy exposure. The Lancet 1999;354:1441-42.
Practical Perinatal Care-The Baby Under 1000 Grams. Gill Levitt, David Harvey, Richard Cooke [\$165.00]. Butterworth Heinemann Hardback ISBN 0-7506-1717-9.

Many will have experienced a feeling of being daunted when beginning a neonatal post as a doctor in training or as a neonatal nurse. The smaller the infant with which to be faced, the greater the concern over the ability to manage the infant appropriately. Levitt, Harvey and Cooke's Practical Perinatal Care-The Baby Under 1000 Grams goes a long way to provide a very readable but authoritative book which will help prepare those in neonatal medical or nurse training to manage these infants. The book has a wide range of chapters from the practical aspects of how to put in an arterial line, perform a suprapubic aspiration of the bladder or drain a pneumothorax, to ventilation strategies, and ethical issues of the management of extremely low birth weight infants. The authors have rightly concentrated on the subgroup of neonatal patients who are less than $1000 \mathrm{~g}$ at birth as these are undoubtedly the most challenging group, where there is the greatest mortality and morbidity, and where there is the possibility to improve the outcome with good care. Each chapter is relatively short but provides clear information from an evidence based perspective where available and is very well referenced. There is an informative chapter on iatrogenic disease which reminds the reader as to the damage which may result from the procedures and treatment given, especially if care is not taken. All chapters conclude with a highlighted box of Practical Points and there are useful diagrams and a series of black and white photographs to aid the text, although occasionally these are too small to be of real value such as in the procedures chapter. Any senior house officer, specialist registrar, or neonatal nurse starting a neonatal post would be well advised to read this useful book which will sit nicely between the several general neonatal texts that are available and the more definitive works which will remain the mainstay of neonatal reference.

ANTHONY J B EMMERSON
Consultant Paediatrician
St Mary's Hospital
Manchester

